\title{
Effective Strategic Positioning of Institutions of Secondary Professional Education in the Knowledge Economy
}

\author{
Julia Aydarova ${ }^{1, *}$, Natalia Pashkus1, and Ivan Blagikh ${ }^{2}$ \\ ${ }^{1}$ Herzen State Pedagogical University, the Moika river emb., 48.St. Petersburg, Russia \\ ${ }^{2}$ St. Petersburg State University, Universitetskaya nab., 7-9, St. Petersburg, Russia
}

\begin{abstract}
The purpose of the article is to develop a strategy for the forming a strong cluster of secondary vocational education in Russia. In the era of globalization, toughening competition in the global education market, high economic and political risks, the development and implementation of an educational institution development strategy requires a search for new approaches and the development of new methods and ways to implement it. The paper proposes a model of breakthrough positioning of institutions of secondary vocational education, by which it is possible to identify effective strategies of institutions and to carry out their ranking. The work carried out the positioning of institutions of secondary vocational education on the modified matrix of Cagan and Vogel and proposed strategies for their development in accordance with the position taken. The article developed a tool for identifying the strategic priorities of institutions of secondary vocational education, which allows to identify promising dominants of the strategic development of organizations and their financing. When using the positioning model, it is shown that not all types of positioning can be effectively used by an organization, and an untimely choice of a more promising strategy can be unsuccessful for an institution.
\end{abstract}

\section{Introduction}

In the era of digitalization of the economy, more and more functions in various spheres of economic activity are performed under the control of information technologies, the development of which is not only sufficient, but also a necessary condition for successful activity in any field. In these conditions, there are many professions that do not require deep theoretical education, but require specific practical skills and knowledge of applied software products and digital devices for the effective performance of professional functionality. Consequently, the demand for graduates of the updated system of secondary vocational education increases.

Moreover, in the context of digitalization of the economy increases the share of selfemployment, providing services for end users and for economic agents. In these conditions, the information environment and the Internet become a means of establishing contacts, finding consumers and customers, and a place, as well as a way of applying the services themselves and individualizing the goods. A large proportion of the self-employed require

\footnotetext{
*Corresponding author: yulia185@mail.ru
} 
narrow but deep and specific skills and technological support that will enable them to sustainably lead the competition for orders and consumers in the global service market.

Many companies today virtually abandon real offices and permanent staff, transferring a significant share of functions to outsourcing or receiving them as a result of free competition on the Internet. At the same time, the boundaries between countries and companies are blurred, the best specialists perform the required functions, and the costs of companies are significantly reduced. Spontaneous teams of specialists belonging to different cultures, speaking different languages, separated from each other geographically, but performing the same task required by a particular project, can arise in the network. At the same time, information network technologies become the basic conditions for the formation of such teams and the execution of tasks solved by them. [1]

The growth of requirements for obtaining practical professional competencies in demand in the digital world is changing the conditions for the development of the system of special professional education. In the digital economy, SVE institutions find it more difficult to compete, not only with each other in a particular region, but also with SVE institutions in other regions and even countries, as educational conditions outside the students ' home region become easier. We have to compete with the self-employed in the provision of educational services, as well as with all sorts of on-line courses, often performed at a very high level and guarantee the effective acquisition of the necessary practical skills of students. Consequently, the competitive environment of SVE institutions in the digital economy is becoming complex and characterized by a high level of uncertainty. Moreover, these institutions must correct the imbalance in human capital, which is necessary for innovative development. [2]

Indeed, in today's economic conditions, it is increasingly important to ensure the development of a quality system of professional training of citizens at all levels. As noted by the Nadegda Starobinskaya and Anna Koltsova [3], the demands of the digital economy, the growth of innovation processes, globalization, the integration of capital markets and the formation of economic and political alliances create new requirements for the activities of the education system and the quality of its educational services. The need for innovative development is associated with the education system, it is able to provide the necessary impetus and ensure the pace of development. [4, 5] Finally, good SVE institutions can act to strengthen cultural brand. [6] All this brings to the fore of need to improve the competitiveness of educational institutions, which corresponds to the economic policy implemented in Russia and the expectations of economic growth. [7, 8]

The system of secondary vocational education (SVE) in many countries, including Russia, is the weakest link. This system should form narrowly focused, but highly practiceoriented professional competences, which makes it possible to efficiently distribute resources in the education system. [9]. Currently, there is a certain reassessment of employers' requirements for employees, as a result of which the employer often makes excessive demands on the employee performing technical functions. There is also dissatisfaction on the part of young professionals who have received higher education, both with their labor functionality, which does not correspond to the level of training of the graduate, and with the proposed salary. [10] In addition, the advent of the digital economy leads to job losses and forces the employee not only to improve their skills, but often learns again. At the same time, the employer is in dire need of highly specialized workers with stronger practical skills. [11] It is these professionals can provide him with the SVE system. This system helps to form the basis of the entrepreneurial orientation of society, to create conditions for self-employment of citizens, to ensure the development of a strong cluster of small and medium-sized businesses in the country. $[12,13]$ Note that the SVE system allows, as noted by Tomas Kliestik and Victor Dengov [14], to reduce social risks arising in the difficult economic conditions of modern Russia. Reduce social risks and returns on education. [15] 
The relevance of research in the field of SVE management problems is due to a number of objective reasons: the importance of obtaining quality education for the personal development of the individual, the need for compliance of the SVE system with the modern realities of socio-economic development. There is also the problem of ensuring the competitiveness of the institutions of str, both among competing organizations in the sector of secondary vocational education, and among educational institutions in General. This is due to the above-mentioned problem of reassessment of the requirements of employers, who prioritize hiring graduates on the functional and salary corresponding to the graduate of the str. Consequently, str institutions have to compete with other str and universities within the country, as well as participate in global competition with similar institutions. $[2,16]$ the latest trend requires the use of new positioning tools in the educational services market. Thus, the aim of the study is to adapt the strategy of breakthrough positioning to specific types of SVE institutions.

\section{Methodology: Model of Breakthrough Positioning and Assessment of SVE Competitiveness}

One such tool is the breakthrough positioning strategy. This strategy involves the division of all SVE institutions into four categories in accordance with the dominant features in their promotion, which can become key success factors or, if the emphasis is wrong, cause inattention to educational organizations by stakeholders and, as a result, become uncompetitive. As a primary basis, positioning is carried out in accordance with the authors ' modified positioning map of Jonathan Cagan and Craig M. Vogel. [17] The resulting matrix (Fig. 1) has four quadrants in accordance with a combination of stylistic and technological (innovative) factors, which allows to divide all educational organizations into four groups (generics, kitsch, high-tech and breakthrough), for each of which offers its own approaches to positioning.

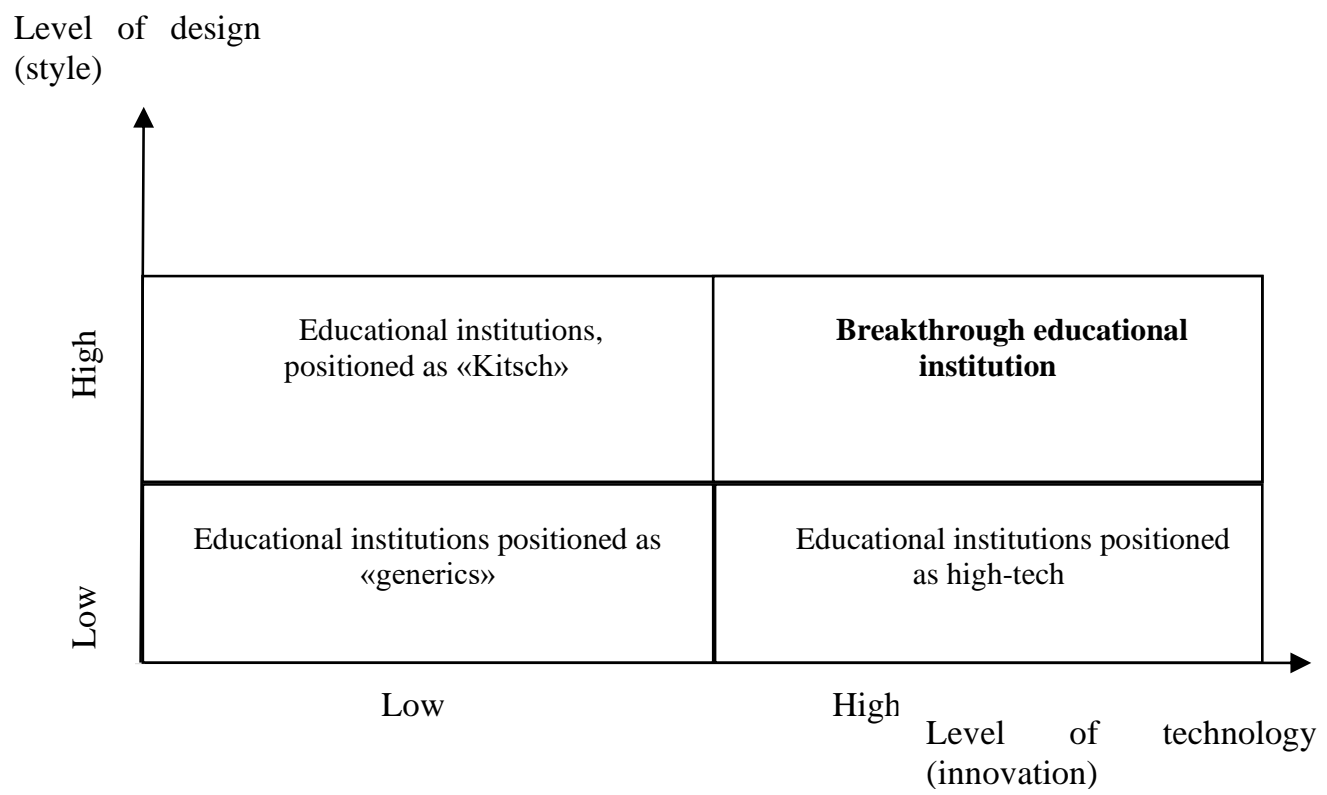

Fig.1. Modified map positioning of Cagan and Vogel 
Generic (standard SVE with a minimum of differentiating properties), kitsch (SVE stylistically eye-catching, fashionable, are on the ear, and sometimes infamous), innovative (basing its strategy on technological dominance used innovative schemes and methods of work) and breakthrough (institution, combining in its strategy as a stylistic and innovative design features to the maximum extent). The implementation of a breakthrough strategy for the development of the institution will allow it to achieve sustainable competitive advantages, both in the domestic market and in global competition, moreover, will successfully compete with some universities, and justify to the employer, including foreign, the level and quality of training of its graduates. [18, 19]

An example of the implemented strategy of breakthrough positioning is the Academy of Russian ballet. A. Ya. Vaganova (price: 400 thousand rubles per year) or St. Petersburg art school. N. K. Roerich (316,6 thousand rubles), close to them and the strategy of The Academy of beauty industry "Lock" (120.8 thousand rubles). The breakthrough strategy employed by these institutions allows them to maintain consistently high prices for their educational programs without losing potential applicants. These institutions are able to compete successfully with other SVE institutions in St. Petersburg, Russia and even abroad, as well as with universities of similar professional areas. [20] the Success of a breakthrough the positioning of these SVE is determined by their abilities in the closure of the SET-gap (combined in the strategy of the institution and positioning strategies of the dominant social demands for professionals with this profile, the study of economic and technological factors of their quality training).

It should be noted that the successful competitive position of the str institution and its financial results depend on the correctly chosen positioning and promotion strategies in the relevant market. Therefore, it would be appropriate for the establishment of the str to develop an effective strategy for the implementation of breakthrough positioning. However, it should be borne in mind that this strategy is quite risky and may not be effective in all conditions. Thus, it is expedient for SVE institutions to determine strategic positions promising for themselves for all strategic directions, and to make a choice in favor of one of the types of positioning consciously.

To clarify the basic strategies (in accordance with the Cagan-Vogel positioning map), it is possible to consider the main characteristics of SVE institutions that fall into the corresponding position using the modified GE/McKinsey competitiveness matrix. For the four positioning strategies, four types of strategic models can be constructed to identify the main dominants of the strategic development of str institutions. At the same time, the competitive position of the SVE institutions can be assessed by two types of criteria: Xhorizontal axis, represents the competitive status of the SVE institution in its field of competence when choosing a specific type of positioning with a focus on typical activities (generics), stylistic differences and elite approach (kitsch), innovative and technological orientation and the use of breakthrough approaches, and Y-vertical axis, is determined by the attractiveness of the selected direction of positioning for a specific subject area of the SVE institution.

Thus, the factor $\mathrm{X}$ include:

1. Relative market share of SVEs;

2. The spread of income from paid programs, the volume of attracted financing (both on the state order and paid services rendered and other commercial activities, as well as fundraising projects);

3. The ability to compete on prices and quality of services provided in the digital economy, i.e. not only with other domestic SVE institutions, but also with foreign institutions, individuals and free collectives providing similar educational services through the network;

4. Technological advantage; 
5. Marketing advantage;

6. Ability to manage effectively;

7. Consumer and SVE market knowledge in the digital economy;

8. Flexibility in the implementation of the str strategy and its ability to manipulate the modern digital environment in order to achieve sustainable competitive advantages.

The second group of criteria that make up the vertical integral indicator includes:

1. The size of the str market in the selected direction of positioning and its growth rate;

2. Features of competition in the chosen field of activity;

3. The profitability of the str market or the attractiveness of its strategy in the social sphere and in terms of competition for the provision of educational services to the state;

4. Requirements for technologies and investments in the str market;

5. Barriers to entry and exit to the subject market str with a similar positioning strategy;

6. Dependence on external threats and the influence of the digital environment.

Evaluation of the competitive status of the institution str can be done using a modified methodology of analytic hierarchy process (AHP) and procedures for calculating the marginal replacement coefficients of each criterion.

\section{Results}

Thus, we present models for assessing the competitive positions of SVE institutions when they choose different types of strategic positioning in the market.

For SVE-generics, the strategic positioning model can be represented by the following matrix (see Fig. 2):

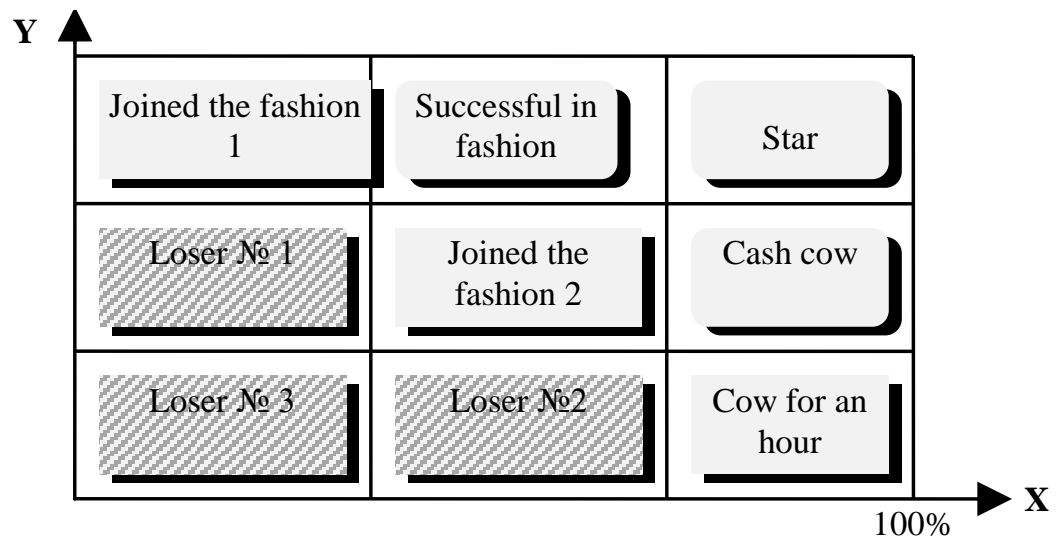

Fig. 2. Matrix of positioning of SVE-generics in the market

For SVE-generics, indicators of competitiveness and attractiveness of the market will take into account their social and economic orientation. [21] the star area is the undisputed market leader for them. Such a SVE institution is able to maintain this position because of the uniqueness of training programs and a strong brand, both among consumers and employers or in the control bodies in the education system. "Cash cow" is a good option for the development of the promotion strategy, which allows for a long time to operate the SVE brand, in this case, the educational institution receives additional financial flows and attracts consumers for old achievements. 
The area of "successful in the fashion market" corresponds to the implementation of str strategies, which were able to integrate into the existing strong demand for a certain soughtafter professional direction. Leadership in this position can be achieved at the expense of low costs of implementation of fashionable educational activities while maintaining the trend of fashion and demand for the profession. The position of "cow for an hour" assumes temporary leadership of the SVE institution due to the previously established image of a previously attractive professional direction, which may not be consistently in demand. For some time, SVE institutions such as cash cows will be prioritized by consumers, but their competitive advantages are short-term. "Joined the fashion" SVE institutions are focused on the currently popular professional areas, the leaders of which are other SVE institutions. In this position, the position of SVE is stable as far as stable demand for this area and a strong competitive advantage companies in this direction, although usually they are wealthy only in the short term.

For innovative SVEs, the positioning model is shown in Fig. 3.

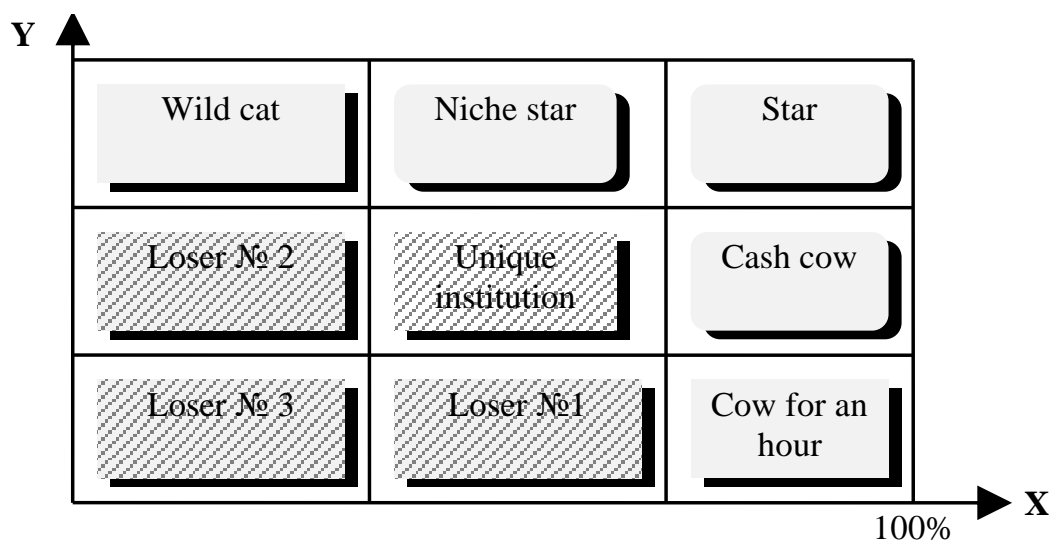

Fig. 3. Matrix of positioning of innovative SVE institutions

For these SVEs, a high level of technology development and innovation is a determining factor, so if the str institution and its programs have unique technological characteristics, it is able to take a leading position in the market of educational services of this level. Such SVEs are consistently the stage of "wild cat" and "niche stars", and to eventually achieve a leading position and become a "star".

SVE-"wild cat" in this interpretation of the model is an invader of resources, an institution implementing an aggressive promotion strategy, their positions are somewhat ambiguous and the future is at the stage of formation. If the chosen strategy of SVE promotion is successful and the institution is able to properly allocate resources and implement the promotion, then it can turn from a "wild cat" into a "niche star". The young star corresponding to the leading market position in the market of SVE will be the leader in some segment of the professional market. However, the maintenance of this strategy is quite expensive for the institution, and the conscious choice of innovative direction supported by the str, the consumer is not always carried out. In order to become a "star", it is necessary to develop the social significance of the innovative professional direction and to convey to the consumer and the employer the consistency of the applied innovations.

The established star with a decrease in the attractiveness of the professional market can provide a transition to the position of "cash cow", which will ensure the competitiveness of the SVE institution for a certain period, allowing it to lead the niche position. "Cow for an 
hour" is a SVE joined the innovation leader by copying the applied technologies and educational innovations.

For SVE-«kitsch" positioning model is shown in Fig. 4.

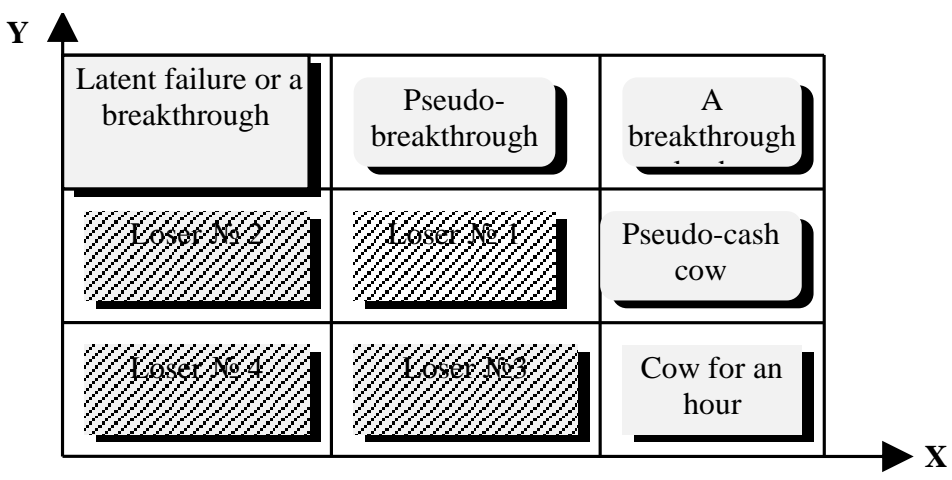

Fig. 4. Matrix positioning for SVE- «kitsch»

"Wild cat" in accordance with this model is an institution SVE, the idea of promoting which has already taken shape, but the actual promotion of which has not yet been implemented. These institutions and their programs do not have technological and innovative ideas, their novelty lies in being presented in an exclusive position or promoted in an atypical way. If the idea of promoting a SVE institution works, it becomes a "young star", i.e. begins to lead in a certain narrow segment of the elite category of professional institutions, its services are considered"unique". If the SVE part of the wide Vogue among the ecstatic audience, then it becomes a classic star. When such a star loses its appeal, then there is no need to support it further. At the same time, there are other SVE institutions that focus on the solvency of the leader of «kitsch" and try to join his successful professional direction. As a result, there is a "cow for an hour", a SVE, which is able to compete for a short period of time, while some representatives of the elite market of the former star still wish to receive a previously leading profession. "Cow for an hour" is positioned in a slightly different consumer audience, but with the same idea. In case of further loss of market attractiveness or reduction of competitive status of the SVE-" kitsch" falls into the group of "transitional", which are not stable. "Transition No. 1" SVE is somewhat better due to higher attractiveness of vocational guidance, for "transition \# 2" the need to have to look novopriobreteniem direction, so as to promote it as planned - failed. If these SVE fail to advance to the leading zone, they will move to the losers, which for them means the absolute collapse of the component of their ideas of development. Supporting the losers of the PDF - "keech" makes no sense. 
For breakthrough positioning SVE model is shown in Fig. 5.

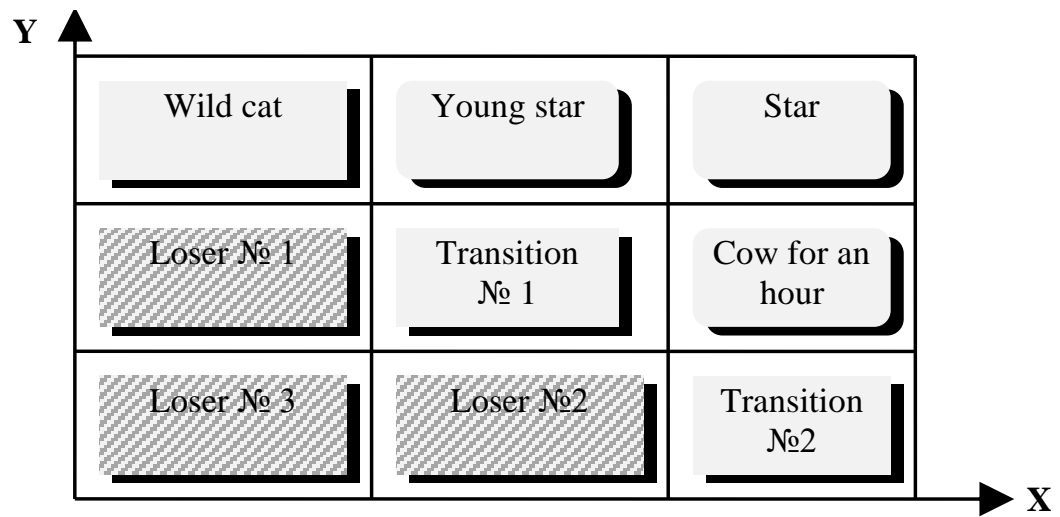

Fig. 5. Matrix positioning for breakthrough SVE institutions

The difference between the positioning matrix for breakthrough SVE institutions is, first of all, the fact that this model has more losing positions. Being unable to close the SET-gap as breakthrough SVEs, they become completely untenable. Thus, it makes no sense to support losing strategies.

"Latent or abortive breakthrough" SVE assumes the presence of breakthrough ideas and technological progress (innovation or socially popular) qualities underlying the competitive strategy, i.e. availability of breakthrough ideas. If the idea was wealthy, the establishment of the SVE can become a "breakthrough leader" when fully closed SVE-open and at a certain slack of the individual components companies act (often technological novshevstv), it will be "pseudoproline". Weakening the attractiveness of competitive preimushestvenno SPO will mean a transition to the "pseudophoenix cows", which to the outside world seem highly profitable, but in fact their hold on the market requires the implementation of permanent low cost. Thus, their competitive advantages are actually untenable. "Cows for an hour" here represent competitors in the field of SVE, who are trying to join the seemingly attractive market, in fact, is already losing its appeal, so the operation of this position is short-term and not very promising (especially compared to the cost of breakthrough positioning).

\section{Discussion}

Despite the fact that the empirical results obtained by the authors in the study of cases on the SVE institutions in the market of St. Petersburg confirm the effectiveness of the applied strategic decisions in accordance with the strategies of breakthrough positioning. However, the authors regret to note that the vast majority of the study sample carried out a successful positioning intuitively rather than relying on kaike any marketing tools.

It should be noted that the application of the breakthrough positioning model allows to get an idea of the competitiveness of educational institutions. However, the application of this model has significant limitations. These limitations are associated with the marketing orientation of the model, with the problems of adequate valuation of intangible assets, with the lack of orientation of the model to the global market, with the actions of the state. Thus, Anna Surzhikova, Yuri Ermakov and Alla Kirillovskaya [21] show that the use of marketing tools without a solid strategic component can lead to problems in the long term and cognitive dissonance on the part of consumers. According to Zhamilya Aliaskarova [22], the assessment of both intangible assets of the organization and the motivation of consumers in modern conditions is much more difficult, which makes the choice of a positioning model 
difficult. Moreover, the SVE institutions, as a rule, do not have the means to adequately analyze their resources and motivate the target audience. Gennady Alpatov and Elena Bortnikova [23] argue that the requirements for the typification of educational institutions can cut off the most promising options for the strategy. In addition, the educational policy pursued in Russia seriously limits educational institutions in their capabilities, including those related to orientation to the global educational market. As emphasized by Anna Volkova and Alla Kirillovskaya [24, 25], we should not forget about the restrictions on the part of the state and the compliance of promotion strategies with state policy. However, active research on this issue will improve the model and get more adequate results.

\section{Conclusion}

Thus, the digital economy is changing the economic environment and priorities of students who tend to get more practice-oriented skills, including a good command of applied information technologies and devices. The focus on practical skills and the growth of selfemployment is leading to a tightening of the requirements for the operation of the str system in all countries. Thus, the competitive environment in the field of SVE is toughened. Developed in the article modeling tool and methods of calculation of competitiveness, provides SVE institutions new analytical capabilities, which gives them the opportunity to choose the right strategic decision. With the help of the proposed tools, the SVE institution can independently study its own strategic opportunities or compare its competitive positions with the positions of other players in this market. The analysis of the existing conditions of development, resource potential and strategic opportunities will allow the establishment of the SVE to more consciously choose a strategic direction and highlight the most important dominants of development. Moreover, the correct strategic positioning of the SVE institution will allow it to succeed in the era of digitalization, will enable it to compete effectively in the chosen professional field, enter into profitable partnerships and ensure sustainable economic growth in the chosen professional market.

\section{References}

1. E. Kamenica Information Economics. Journal of Political Economy, 125, 1885-1890 (2017)

2. S.W. Polachek, T. Das, R Thamma-Apiroam. Micro- and Macroeconomic Implications of Heterogeneity in the Production of Human Capital. Journal of Political Economy, 123, 1410-1455 (2015)

3. A. A. Koltsova, N.M.Starobinskaya. Improving the quality and effectiveness of education in the New Economy. Marketing MBA. Marketing management firms, 5, 137149 (2014)

4. P. Segerstrom. Innovation, Imitation, and Economic Growth. Journal of Political Economy, 99, 807-827 (1991)

5. Y.C.L. Zhang. Human Capital, Technology Adoption and Firm Performance: Impacts of China's Higher Education Expansion in the Late 1990s. The Economic Journal, 128, 2282-2320 (2018)

6. V. Y. Pashkus et al. Evaluation of City Brand in the Global Economy: Techniques and Perspectives. Globalization and its Socio-Economic Consequences. 16th International Scientific Conference Proceedings. Zilina, Rajecke Teplice, Slovak Republic, 16351641 (2016) 
7. A. Belov et al. Universities' Competitiveness Models in Academic Management: a National-Level Approach. Management Theory And Studies for Rural Business and Infrastructure Development. 40, 155-166 (2018)

8. I. Korhonen, A.N. Lyakin Problems and Prospects of Russia's Economic growth. St Petersburg University Journal of Economic Studies, 33, 36-50 (2017)

9. S. Bowles. The efficient allocation of resources in education. The Quarterly Journal of Economics, 81, 189-219 (1967)

10. V. G. Khalin, G. V. Chernova, Jamil Salmi Model of Establishing World-Class Universities and Implementation of Salmi Model for Higer Education In Russia. Systems Analysis in Engineering and Management. Proceedings of the XVIII International scientific and practical conference. Saint-Petersburg, Russia, 160-170 (2015)

11. Zh.A. Aliaskarova. Breakthrough positioning as a key to the implementation of student exchange in Russia. Notes the Scientist, 8, 12-16 (2016)

12. A. Altunyan, T. Kotcofana. Global Political and Economical Processes, Monetary Policy of the Bank of Russia and Development of the Russian Economy. Globalization and its Socio-Economic Consequences. 16th International Scientific Conference Proceedings. University of Zilina, Zilina, Slovak Republic, 33-40 (2016)

13. V. Plotnikov, Yu. Vertakova, Yu. Polozhentseva. Methods of Detecting Imbalances in the Structure and Dynamics of Socio-Economic System. SGEM 2015. International Multidisciplinary Scientific Conference on Social Sciences and Arts Political Sciences, Law, Finance, Economics and Tourism Conference Proceedings. Sofia, Bulgaria, 2-2, 821-828 (2015)

14. T. Kliestik, V. Dengov, Quantitative Approach to Risk as a Social Phenomenon. 2015 5th International Conference on Applied Social Science, 80, 28-33 (2015)

15. J. J. Heckman, J. E. Humphries, G. Veramendi. Returns to Education: The Causal Effects of Education on Earnings, Health, and Smoking. Journal of Political Economy,126, S197-S246 (2016)

16. A. N. Lyakin, I. N. Benson, Does Globalisation Lead to the Unification of the Institutional Environment Quality? Globalization and its Socio-Economic Consequences. 16th International Scientific Conference Proceedings. University of Zilina, Zilina, Slovak Republic, 1220-1227 (2016)

17. J. Cagan, C. M. Vogel, Creating Breakthrough Products. Innovation from Product Planning to Program Approval. (FT Press, London, 2001)

18. Y. V. Vertakova, I. G. Ershova, V.A. Plotnikov. Educational system influence on knowledge economy formation. World Applied Sciences Journal, 2), 679-683 (2013)

19. R. S. Hunter, A. J. Oswald, B.G.Charlton. The Elite Brain Drain. The Economic Journal, 119, F231-F251 (2009)

20. M. Zaboev, M.Meleshkin. Evaluation of the prospects Russian universities to be among the first hundred of the world's leading universities with the use of neural network methods clustering of data. Applied Informatics, 10, 52-61 (2015)

21. A. V. Surgikova, Y. V. Ermakov, A. A. Kirillovskaya. Modern Organizations in the Sphere of Culture: from Resource Approach to Benchmarking. Marketing MBA. Journal marketing management firms, 7, 132-143 (2016)

22. Zh. A. Aliaskarova. New Economy: New Reality and Motivation of Consumers. Marketing MBA. Journal marketing management firms, 8, 5-15 (2017)

23. G. E. Alpatov, H. G.Bortnikova. Globalization and the Unification of Tertiary Education. Globalization and its Socio-Economic Consequences. 16th International 
Scientific Conference Proceedings. University of Zilina, Zilina, Slovak Republic, 25-32. (2016)

24. A. V. Volkova. State manageability and civil competence. Historical, Philosophical, Political and Law Sciences, Culturology and Study of Art. Issues of Theory and Practice, 4, 44-47 (2014)

25. A. A. Kirillovskaya et al., The Newest Economic Policy, Government Regulation of the Economy and Economic Security. Globalization and its Socio-Economic Consequences. 16th International Scientific Conference Proceedings. Zilina, Rajecke Teplice, Slovak Republic, 870-875 (2016) 